\title{
Attenuation of Ethanol Withdrawal by Ceftriaxone-Induced Upregulation of Glutamate Transporter EAAT2
}

\author{
Osama A Abulseoud ${ }^{*,}$, , Ulas M Camsari', Christina L Ruby ${ }^{2}$, Aimen Kasasbeh', Sun Choi ${ }^{2}$ and \\ Doo-Sup Choi*, ${ }^{\prime, 2}$
}

'Department of Psychiatry and Psychology, Mayo Clinic College of Medicine, Rochester, MN, USA; ${ }^{2}$ Department of Molecular Pharmacology and Experimental Therapeutics, Mayo Clinic College of Medicine, Rochester, MN, USA

\begin{abstract}
Alcohol withdrawal syndrome (AWS) is a potentially fatal outcome of severe alcohol dependence that presents a significant challenge to treatment. Although AWS is thought to be driven by a hyperglutamatergic brain state, benzodiazepines, which target the GABAergic system, comprise the first line of treatment for AWS. Using a rat model of ethanol withdrawal, we tested whether ceftriaxone, a $\beta$-lactam antibiotic known to increase the expression and activity of glutamate uptake transporter EAAT2, reduces the occurrence or severity of ethanol withdrawal manifestations. After a 2-week period of habituation to ethanol in two-bottle choice, alcohol-preferring (P) and Wistar rats received ethanol $(4.0 \mathrm{~g} / \mathrm{kg})$ every $6 \mathrm{~h}$ for $3-5$ consecutive days via gavage. Rats were then deprived of ethanol for $48 \mathrm{~h}$ during which time they received ceftriaxone $(50$ or $100 \mathrm{mg} / \mathrm{kg}$, IP) or saline twice a day starting $12 \mathrm{~h}$ after the last ethanol administration. Withdrawal manifestations were captured by continuous video recording and coded. The evolution of ethanol withdrawal was markedly different for $\mathrm{P}$ rats vs Wistar rats, with withdrawal manifestations occurring $>12 \mathrm{~h}$ later in $\mathrm{P}$ rats than in Wistar rats. Ceftriaxone $100 \mathrm{mg} /$ $\mathrm{kg}$ per injection twice per day $(200 \mathrm{mg} / \mathrm{kg} /$ day $)$ reduced or abolished all manifestations of ethanol withdrawal in both rat variants and prevented withdrawal-induced escalation of alcohol intake. Finally, ceftriaxone treatment was associated with lasting upregulation of ethanol withdrawal-induced downregulation of EAAT2 in the striatum. Our data support the role of ceftriaxone in alleviating alcohol withdrawal and open a novel pharmacologic avenue that requires clinical evaluation in patients with AWS.

Neuropsychopharmacology (2014) 39, 1674-1684; doi:I0.1038/npp.2014.14; published online 19 February 2014
\end{abstract}

Keywords: animal models; glutamate; glutamate transporter; ceftriaxone; ethanol withdrawal; alcohol-preferring rats

\section{INTRODUCTION}

Alcohol withdrawal syndrome (AWS) is a medical emergency associated with high mortality rates (Campos et al, 2011). The neurobiological mechanisms underlying AWS are complex, but generally involve neuroadaptation triggered by the chronic presence of alcohol, a CNS depressant, which leads to hyperexcitability upon termination of ethanol intake (Tsai et al, 1998; Hinton et al, 2012). This hyperexcitability is mediated by disruption in the balance between inhibitory GABAergic and excitatory glutamatergic neurotransmission, with reduced CNS levels of GABA and GABA receptor insensitivity (Crews et al, 2005) as well as overactivation of glutamatergic neurotransmission (Tsai et al, 1998).

Currently, benzodiazepines are the drugs of choice for the treatment of AWS (reviewed by Amato et al, 2011). These

* Correspondence: Dr OA Abulseoud or Dr D-S Choi, Department of Psychiatry and Psychology, Mayo Clinic College of Medicine, 200 First Street SW, Rochester, MN 55905, USA, Tel: + I 5072557164 (OAA) or + I 5072845602 (D-SC), Fax: + I 5072550707 (OAA) or + 5072660824 (D-SC), E-mail: Abulseoud.Osama@mayo.edu or choids@mayo.edu

Received 8 September 2013; revised 10 January 2014; accepted 13 January 2014; accepted article preview online 23 Janaury 2014 compounds potentiate GABA-A receptor signaling and act to counterbalance the hyperexcitation produced by excessive glutamate transmission. However, benzodiazepine treatment of AWS has substantial drawbacks, including its own host of rebound effects upon cessation of treatment and increased risk of relapse into alcohol dependence following its withdrawal (Malcolm, 2003). Other nonbenzodiazepine compounds such as carbamazepine, gabapentin, valproic acid, topiramate, gamma-hydroxybutyric acid, baclofen, and flumazenil have been studied, but have been associated with limited clinical efficacy (Leggio et al, 2008). These studies underscore the urgent need to discover novel treatments of AWS and to develop clinically relevant animal models thereof (Ripley and Stephens, 2011).

Ceftriaxone is a $\beta$-lactam antibiotic known to increase glutamate reuptake through the induction of glial EAAT2 expression (Rothstein et al, 2005). As ceftriaxone has been shown to reduce synaptic glutamate levels in animal models of drug addiction (Abulseoud et al, 2012; Knackstedt et al, 2010) and decrease ethanol consumption in alcoholpreferring (P) rats (Sari et al, 2011) and mice (Lee et al, 2013), we hypothesized that it may represent a promising candidate for treating AWS. Here, we used video tracking to characterize the detailed time course of severe alcohol withdrawal manifestations over $48 \mathrm{~h}$ in rats. Given the high 
rates of withdrawal among individuals in binge-drinking situations (Plant et al, 2012), we used Wistar rats, a model of moderate drinking, and $\mathrm{P}$ rats, an alcohol-preferring model (Kampov-Polevoy et al, 2000; Waller et al, 1982). We then tested the efficacy of ceftriaxone in reducing ethanol withdrawal symptoms and examined whether ceftriaxone would prevent the escalation of ethanol intake seen following alcohol withdrawal. Finally, we investigated whether ceftriaxone treatment upregulated EAAT2 in corticostriatal circuitry.

\section{MATERIALS AND METHODS}

\section{Animals}

Adult male $\mathrm{P}$ rats $(n=36$, Indiana University) and Wistar rats ( $n=36$, Charles River Laboratories, Wilmington, MA, USA), 12-16 weeks old, were housed in standard Plexiglas cages with food and water available ad libitum. The chamber was maintained on a 12-h light/12-h dark photocycle (lights on at 0600 hours) at the temperature $\left(69-71^{\circ} \mathrm{F}\right)$ and humidity $(\sim 50 \%)$ were controlled. Animal care and handling procedures were approved by the Mayo Clinic Institutional Animal Care and Use Committees in accordance with NIH guidelines.

\section{Voluntary Ethanol Consumption}

Rats were given 24-h access to two bottles, one containing plain tap water and the other containing $20 \%$ ethanol ( $/ \mathrm{v}$ in tap water), for 2 weeks before and 1 week following ethanol gavage and withdrawal monitoring (described below). Fluid intake and body weight were measured every $48 \mathrm{~h}$ to calculate average ethanol consumption ( $\mathrm{g} / \mathrm{kg} /$ day).

\section{Ethanol Gavage}

Nasogastric gavage ethanol administration was used to induce severe alcohol intoxication and subsequent withdrawal (Collins et al, 1996; Nixon and Crews, 2004). Briefly, ethanol $(4 \mathrm{~g} / \mathrm{kg}, 40 \% \mathrm{v} / \mathrm{v})$ was administered via a soft nasogastric tube $\left(3.5^{\circ} \mathrm{F}\right)$ at four time points $(0600,1200,1800$ and 2400 hours) for 3-5 consecutive days. We used 3-day gavage for $\mathrm{P}$ rats and 5-day gavage for Wistar based on our observation of their differential intoxication thresholds. Rats that were unable to move in response to a paw pinch skipped one ethanol administration dose and were re-examined $6 \mathrm{~h}$ later. After the 3- or 5-day gavage period, rats underwent $48 \mathrm{~h}$ of ethanol deprivation during which their withdrawal manifestations were monitored and scored (described below). Rats were then reintroduced to ethanol with the two-bottle paradigm for 1 week (above, see Figure 3a).

\section{Withdrawal Manifestations}

Continuous video recording (Nuvico E-800, Englewood, NJ, USA) of home cage behavior was performed over $36 \mathrm{~h}$ starting $12 \mathrm{~h}$ after the last ethanol gavage. Each rat recording was reviewed independently and manifestations were coded separately. Coding was performed by a single trained blinded investigator for the following five withdrawal manifestations: (1) Stereotypic movements: repetitive, purposeless movements such as facial muscle shaking, jaw tremors, chewing movement not associated with feeding, side to side or back and forth head swinging, circling, continuous nodding or body rocking, repetitive tail swinging, and forelimb treading (Supplementary Video Clips 1 and 2). (2) Myoclonic head jerks: abrupt twitching movement of the head inconsistent with the behavioral context the rat was engaged in at the time of the jerk (Supplementary Video Clips 3 and 4). (3) Myoclonic body jerks: abrupt twitching movement of the torso, inconsistent with the behavioral context the rat was engaged in at the time of the jerk (Supplementary Video Clips 5 and 6). (4) Spontaneous, unprovoked startle: abrupt and intense activity that resembles an anxious panic-like response in the absence of a stimulus (Supplementary Video Clips 7 and 8). (5) Spontaneous tonic/clonic seizure: rhythmic myoclonic contractions of at least two limbs that results in the rat falling on its side and that lasts for at least $5 \mathrm{~s}$ (Supplementary Video Clips 9 and 10). We have developed this novel method of home cage continuous monitoring to identify and quantify clear individual withdrawal manifestations reminiscent of clinical withdrawal rating scales.

\section{Ceftriaxone Administration}

To test the efficacy of ceftriaxone in preventing the occurrence or severity of withdrawal manifestations, rats were given ceftriaxone 100 or $200 \mathrm{mg} / \mathrm{kg} /$ day IP (50 or $100 \mathrm{mg} / \mathrm{kg}$ per injection, twice a day for 2 days) or saline (IP) beginning $12 \mathrm{~h}$ after the final administration of ethanol. We used two doses of ceftriaxone; 100 and $200 \mathrm{mg} / \mathrm{kg} / \mathrm{day}$ following the original study by Rothstein et al (2005), which showed that ceftriaxone $200 \mathrm{mg} / \mathrm{kg} /$ day administered to rats for 5 days was associated with a threefold increase in EAAT2 protein expression in the hippocampus and spinal cord. Along with others (Sari et al, 2011, 2013; Knackstedt et al, 2010; Lee et al, 2013), we (Abulseoud et al, 2012) have shown significant efficacy for ceftriaxone $200 \mathrm{mg} / \mathrm{kg} /$ day in upregulating glutamate transporter in different models of addiction.

\section{Western Blot}

Rats were anesthetized with carbon dioxide and rapidly decapitated. Brains were quickly removed and dissected to isolate the striatum and prefrontal cortex (PFC). We chose the whole striatum (nucleus accumbens (NAc), caudate, and putamen) and isolated medial PFC (mPFC), which includes mostly anterior cingulate, infralimbic, and prelimbic cortex, which mainly projects its axons to the striatum (Gerfen and Surmeier, 2011). Western blotting was performed as previously described (Lee et al, 2013). Briefly, tissues were homogenized in an extraction buffer containing $50 \mathrm{mM}$ Tris buffer ( $\mathrm{pH}$ 7.4), $2 \mathrm{mM}$ EDTA, $5 \mathrm{mM}$ EGTA, 0.1\% SDS, protease inhibitor cocktail (Roche), and phosphatase inhibitor cocktail type I and II (Sigma). Homogenates were centrifuged at $500 \mathrm{~g}$ at $4{ }^{\circ} \mathrm{C}$ for $15 \mathrm{~min}$ and supernatants were collected. Proteins were analyzed using Bradford protein assay (Bio-Rad). Equal amounts of proteins (50 mg) were separated by $4-12 \%$ NuPAGE Bis Tris gels at $130 \mathrm{~V}$ for $2 \mathrm{~h}$, transferred onto PVDF membranes at $30 \mathrm{~V}$ for $1 \mathrm{~h}$ (Invitrogen), and analyzed using antibodies against EAAT2 (1:500, Santa Cruz, $60 \mathrm{kDa})$ and GAPDH $(1: 1000$, Millipore, $38 \mathrm{kDa})$ as a control. Blots were developed 
using SuperSignal West Dura Chemiluminescent Substrate (Thermo Scientific, Rockford, IL, USA). Chemiluminescent bands were detected on a Kodak Image Station 4000R scanner (New Haven, CT, USA) and quantified using NIH Image J software. EAAT2 antibody selectivity has been tested by preadsorption test. Although there are a number of limitations to this test (Holmseth et al, 2012), it is widely accepted in immunocytochemistry research.

\section{Statistical Analysis}

Two-way ANOVA with main effects of rat type and time was used to compare the time course of withdrawal manifestations in $\mathrm{P}$ rats $v s$ Wistar rats. Two-way ANOVA with main effects of treatment and time were used to test the efficacy of ceftriaxone in preventing withdrawal manifestations and two-bottle choice ethanol consumption. One-way ANOVA was used to compare relative protein levels for control $v s$ saline $v s$ ceftriaxone-treated rats. ANOVA were followed by Tukey's post-hoc test where significant interactions between main effects were found in order to analyze individual comparisons. Results were considered significant where $P<0.05$.

\section{RESULTS}

\section{Differential Time Course of Withdrawal Manifestations in $\mathrm{P}$ and Wistar Rats}

A marked difference in the time course of all withdrawal manifestations investigated was evident between $\mathrm{P}$ rats and Wistar rats. For stereotypy, two-way ANOVA indicated a significant interaction between rat type and time $\left(\mathrm{F}_{1,591}=2.823, P<0.001\right)$. Tukey's post-hoc testing revealed an earlier onset of stereotypy in Wistar compared with $\mathrm{P}$ rats with the peak for Wistar rats occurring between 12 and $15 \mathrm{~h}$ with a bimodal pattern identified in $\mathrm{P}$ rats where two distinct and delayed peaks in stereotypy occurred between 26 and $43 \mathrm{~h}$ after the final ethanol dose (Figure 1a). For myoclonic body jerks, two-way ANOVA indicated significant main effects of rat type $\left(F_{1,591}=22.208, P<0.001\right)$, time $\left(\mathrm{F}_{1,591}=2.365, P<0.001\right)$, and an interaction between the two $\left(\mathrm{F}_{1,591}=4.409, P<0.001\right)$. Tukey's post-hoc test revealed that Wistar rats showed an earlier and less severe occurrence of body jerks, peaking around 12-16 h after ethanol intoxication, compared with the later and more severe pattern seen for $\mathrm{P}$ rats, whose peak body jerking frequency happened $\sim 30-42 \mathrm{~h}$ after ethanol intoxication (Figure 1b). For head jerks, two-way ANOVA identified significant main effects of rat type $\left(\mathrm{F}_{1,591}=36.165\right.$, $P<0.001)$ and time $\left(\mathrm{F}_{1,591}=3.516, P<0.001\right)$ as well as an interaction between rat type and time $\left(\mathrm{F}_{1,591}=3.642\right.$, $P<0.001)$. Tukey's post-hoc test indicated that $\mathrm{P}$ rats presented with significantly more head jerks in the 20$28 \mathrm{~h}$ time frame following ethanol withdrawal compared with Wistar rats (Figure 1c). Seizure frequency also differed between $\mathrm{P}$ and Wistar rats. Two-way ANOVA indicated significant interaction between rat type and time $\left(\mathrm{F}_{1,591}=5.708, P=0.017\right)$. $\mathrm{P}$ rats did not have seizures during withdrawal, whereas seizures were noted in Wistar rats in the immediate withdrawal period until $21 \mathrm{~h}$ thereafter (Figure 1d). Finally, the frequency of unprovoked startle differed between rat types $\left(\mathrm{F}_{1,591}=11.414, P<0.001\right)$ and observation times $\left(\mathrm{F}_{1,591}=3.379, P<0.001\right)$ with an interaction evident $\left(\mathrm{F}_{1,591}=3.509, P<0.001\right)$ by two-way ANOVA. $\mathrm{P}$ rats showed three discontinuous peaks in startle at 30,32 , and $35 \mathrm{~h}$ after ethanol withdrawal, while unprovoked startle responses were nearly absent in Wistar rats (Figure 1e). Overall, these data show clear and marked differences in the manifestation of ethanol withdrawal between the two rat types; the most notable of which is the time course.

\section{Reduced Severity of Ethanol Withdrawal Manifestations with $200 \mathrm{mg} / \mathrm{kg} /$ day Ceftriaxone Treatment}

Ceftriaxone $200 \mathrm{mg} / \mathrm{kg} /$ day significantly reduced the severity of withdrawal manifestations in both $\mathrm{P}$ rats and Wistar rats (Figure 2). For P rats, two-way ANOVA indicated a significant main effect of treatment on stereotypy $\left(F_{1,443}=13.839\right.$, $P<0.001$; Figure 2a) without a significant main effect of time or the interaction between treatment and time. Ceftriaxone completely abolished body jerks in $\mathrm{P}$ rats (Figure $2 \mathrm{c}$ ), as twoway ANOVA indicated significant main effects of treatment $\left(\mathrm{F}_{1,443}=42.174, P<0.001\right)$, time $\left(\mathrm{F}_{1,443}=2.170, P<0.001\right)$, and an interaction between treatment and time $\left(F_{1,443}\right.$ $=2.182, P<0.001)$. Ceftriaxone also completely abolished head jerks in this group (Figure 2e) as two-way ANOVA revealed significant main effects of treatment $\left(F_{1,443}=25.992\right.$, $P<0.001)$, time $\left(\mathrm{F}_{1,443}=2.073, P<0.001\right)$, and an interaction between the treatment and time $\left(F_{1,443}=2.045, P<0.001\right)$. Finally, for the unprovoked startle in $\mathrm{P}$ rats, two-way ANOVA indicated main effects of treatment $\left(F_{1,443}=9.423\right.$, $P=0.002)$, time $\left(\mathrm{F}_{1,443}=2.308, P<0.001\right)$, and an interaction $\left(\mathrm{F}_{1,443}=2.308, \quad P<0.001\right)$ demonstrating that ceftriaxone eliminated the presentation of this ethanol withdrawal phenotype (Figure 2g).

For Wistar rats, stereotypy was reduced by ceftriaxone (Figure 2b) as two-way ANOVA indicated significant main effects of treatment $\left(\mathrm{F}_{1,591}=24.307, \quad P<0.001\right)$, time $\left(\mathrm{F}_{1,591}=3.957, \quad P<0.001\right)$, and an interaction between treatment and time $\left(\mathrm{F}_{1,591}=2.572, P<0.001\right)$. Body jerks were almost eliminated by ceftriaxone (Figure $2 \mathrm{~d}$ ) as twoway ANOVA revealed significant main effects of treatment $\left(\mathrm{F}_{1,591}=17.711, P<0.001\right)$, time $\left(\mathrm{F}_{1,591}=2.308, P<0.001\right)$, and an interaction between treatment and time $\left(\mathrm{F}_{1,591}=1.702, P=0.008\right)$. Head jerks were also significantly reduced as a result of ceftriaxone treatment (Figure $2 \mathrm{f}$ ) as two-way ANOVA indicated significant main effects of treatment $\left(\mathrm{F}_{1,591}=16.263, P<0.001\right)$, time $\left(\mathrm{F}_{1,591}=2.478\right.$, $P<0.001)$, and a treatment $v s$ time interaction $\left(\mathrm{F}_{1,591}=1.947, P=0.001\right)$. However, no significant change in seizure frequency was seen as a result of ceftriaxone treatment in Wistar rats as there was not a significant main effect of treatment $\left(\mathrm{F}_{1,591}=2.035, \quad P=0.154\right.$; Figure $2 \mathrm{~h})$. Together, these data support the conclusion that ceftriaxone treatment alleviates many of the behavioral manifestations observed during alcohol withdrawal symptoms.

Ceftriaxone $100 \mathrm{mg} / \mathrm{kg} /$ day had an inconsistent effect on the severity of ethanol withdrawal manifestations in both $\mathrm{P}$ and Wistar rats. This inconsistency forced us to analyze the data separately and plot it in a different figure (Supplementary Figure 1). For P rats, ceftriaxone $100 \mathrm{mg} / \mathrm{kg} /$ day did not show 
any significant main effect of treatment on reducing the duration of stereotypic behaviors $\left(\mathrm{F}_{1,10}=0.04, P=0.8\right.$; Supplementary Figure S1A), the frequency of body jerks $\left(\mathrm{F}_{1,10}=0.4, P=0.5\right.$; Supplementary Figure $\left.\mathrm{S} 1 \mathrm{C}\right)$, head jerks $\left(\mathrm{F}_{1,10}=1.38, P=0.26\right.$; Supplementary Figure $\left.\mathrm{S} 1 \mathrm{E}\right)$, or unprovoked startle response $\left(\mathrm{F}_{1,10}=1.71, P=0.2\right.$; Supplementary Figure S1G) by two-way ANOVA.
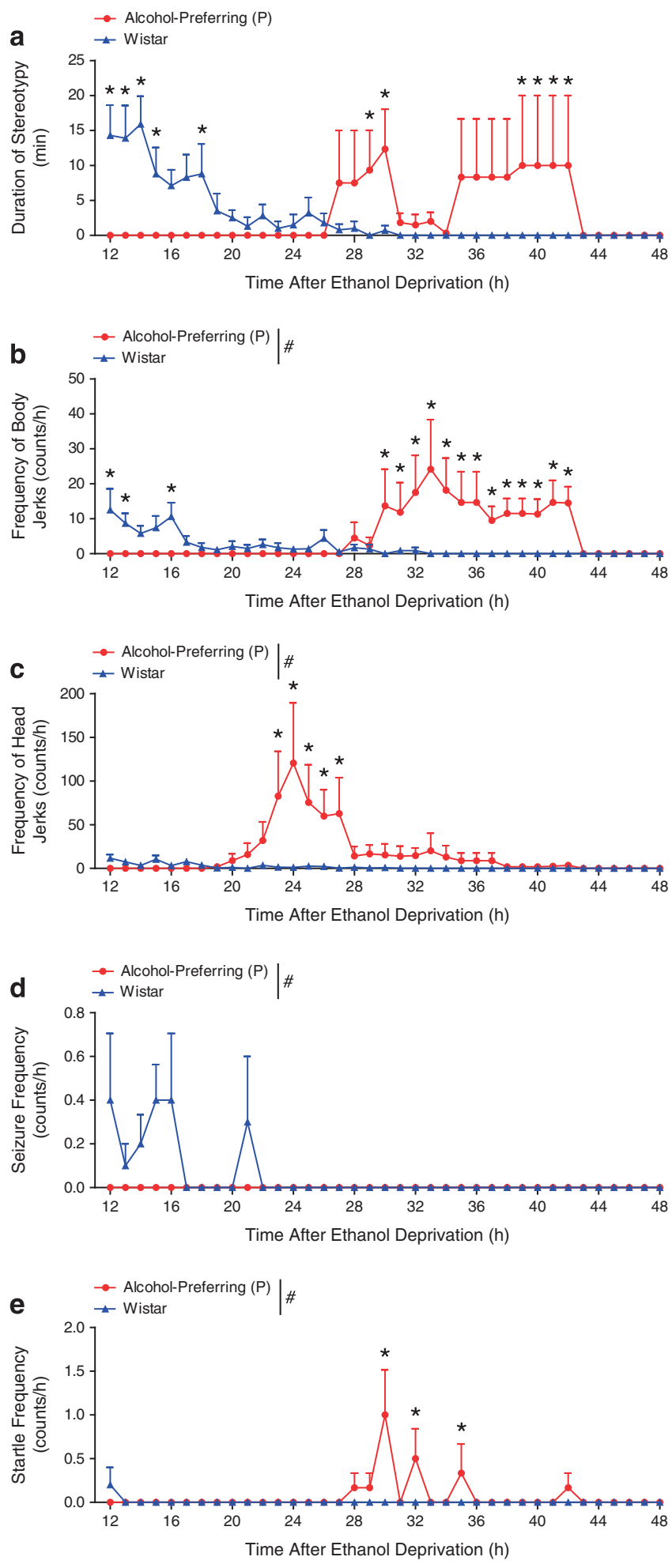

For Wistar rats, ceftriaxone $100 \mathrm{mg} / \mathrm{kg} /$ day did not have an overall significant main effect of treatment $\left(F_{1,14}=0.05\right.$, $P=0.8$, Supplementary Figure S1B), on the duration of stereotypic behaviors by two-way ANOVA. However, it seems that ceftriaxone $100 \mathrm{mg} / \mathrm{kg} /$ day reduced the duration of stereotypic behaviors initially but during the second day of withdrawal (see the time point $28 \mathrm{~h}$ ), the group treated with ceftriaxone $(100 \mathrm{mg} / \mathrm{kg} /$ day $)$ actually spent significantly more time exhibiting stereotypic behavior compared with the saline control group $(P<0.05)$. On the other hand, ceftriaxone $(100 \mathrm{mg} / \mathrm{kg} /$ day $)$ had significant main effect of treatment $\left(\mathrm{F}_{1,14}=2.20, P=0.05\right)$, time $\quad\left(\mathrm{F}_{36,504}=2.46\right.$, $P<0.0001)$, and an interaction between treatment and time $\left(F_{36,504}=2.56, P<0.0001\right.$, Supplementary Figure S1D) on reducing the frequency of body jerks as well as significant main effect of treatment $\left(\mathrm{F}_{1,14}=1.43, P=0.04\right)$, time $\left(\mathrm{F}_{36,504}=2.29, \quad P<0.0001\right)$, and an interaction between treatment and time $\left(\mathrm{F}_{36,504}=2.60, P<0.0001\right.$, Supplementary Figure S1F) on head jerks, but no significant overall main effect of treatment $\left(\mathrm{F}_{1,14}=2.39, P=0.14\right.$, Supplementary Figure $\mathrm{S} 1 \mathrm{H}$ ), time, or an interaction between treatment and time on the frequency of seizure by two-way ANOVA.

\section{Prevention of Withdrawal-Induced Escalation in Ethanol Consumption by $200 \mathrm{mg} / \mathrm{kg} /$ day Ceftriaxone Treatment}

Following the ethanol gavage and the 2-day ethanol withdrawal procedure, rats were reintroduced to $20 \%$ ethanol in a two-bottle choice paradigm to examine withdrawal-induced ethanol consumption (Figure 3a). Ceftriaxone significantly reduced ethanol consumption in $\mathrm{P}$ rats. For ethanol consumption, two-way ANOVA indicated significant main effects of treatment $\left(\mathrm{F}_{1,57}=14,34\right.$, $P=0.0004)$, time $\left(\mathrm{F}_{2,57}=40.57, P<0.0001\right)$, and an interaction between the treatment and time $\left(\mathrm{F}_{2,57}=37.29\right.$, $P<0.0001)$. Subsequent Tukey's post-hoc testing revealed that ceftriaxone $200 \mathrm{mg} / \mathrm{kg} /$ day (but not $100 \mathrm{mg} / \mathrm{kg} /$ day) completely blocked withdrawal-increased ethanol consumption for $\mathrm{P}$ rats $(P<0.001$; Figure 3a). Furthermore, $200 \mathrm{mg} /$ $\mathrm{kg} /$ day (but not $100 \mathrm{mg} / \mathrm{kg} /$ day) ceftriaxone also decreased withdrawal-induced ethanol consumption in Wistar rats (Figure $3 \mathrm{~b}$ ), with main effects of treatment $\left(\mathrm{F}_{1,54}=4.33\right.$, $P=0.018)$ and time $\left(\mathrm{F}_{1,54}=5.81, P=0.019\right)$ as well as a

Figure I Different timecourse and severity of withdrawal manifestations in alcohol-preferring $(P)$ and Wistar rats. Following 3-5 day gavage of highdose ethanol (a) stereotypy peaked between 12- I5h after the final ethanol dose for Wistar rats, while in $\mathrm{P}$ rats, such behavior did not occur until 26-43 $\mathrm{h}$ of alcohol deprivation. (b) Similarly, myoclonic body jerks were displayed earlier and to a lesser extent in Wistar rats, resolving after $16 \mathrm{~h}$ of withdrawal, while $P$ rats displayed more frequent body jerks over the majority of the second day of withdrawal. (c) Myoclonic head jerks were markedly more frequent in $\mathrm{P}$ rats than Wistar rats, peaking during the beginning of day 2 of alcohol deprivation. (d) $P$ rats did not show spontaneous tonic/clonic seizure activity, and Wistars showed it infrequently from 12-2I h after alcohol cessation. (e) Wistar rats showed very infrequent unprovoked startle responses at $12 \mathrm{~h}$, while $\mathrm{P}$ rats displayed startle primarily in the middle of day 2 of withdrawal. ${ }^{\#} P<0.05$ for main effect of rat type by two-way ANOVA; $* P<0.05$ by Tukey posthoc test; $n=6-10$ per rat type. Data is expressed as mean \pm SEM. 
Alcohol-Preferring $(\mathrm{P})$
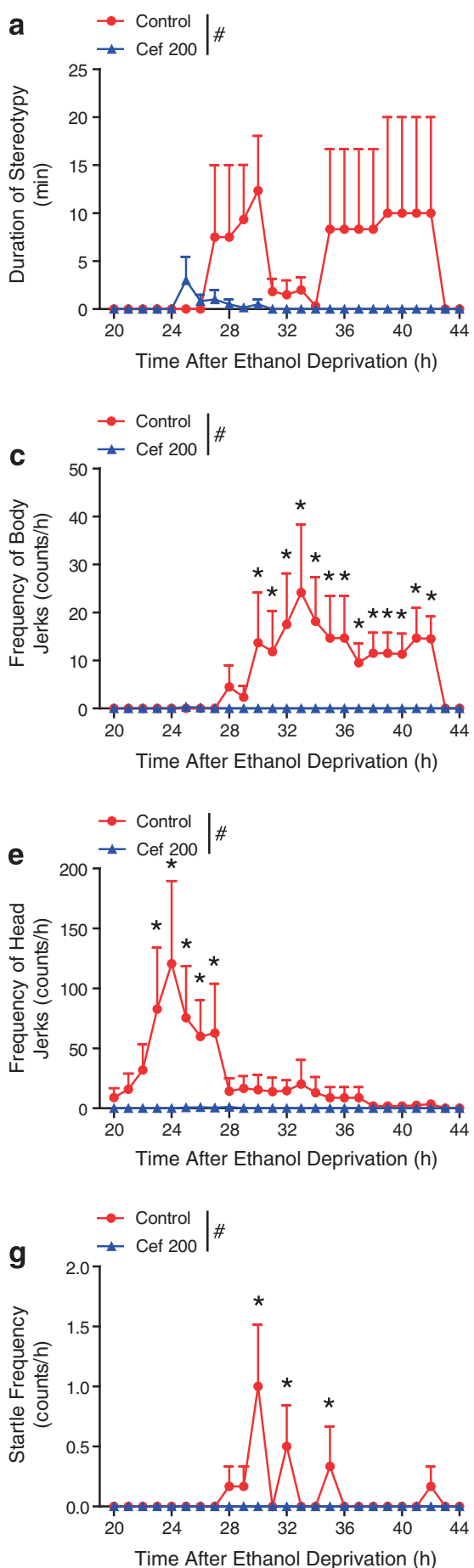

Wistar
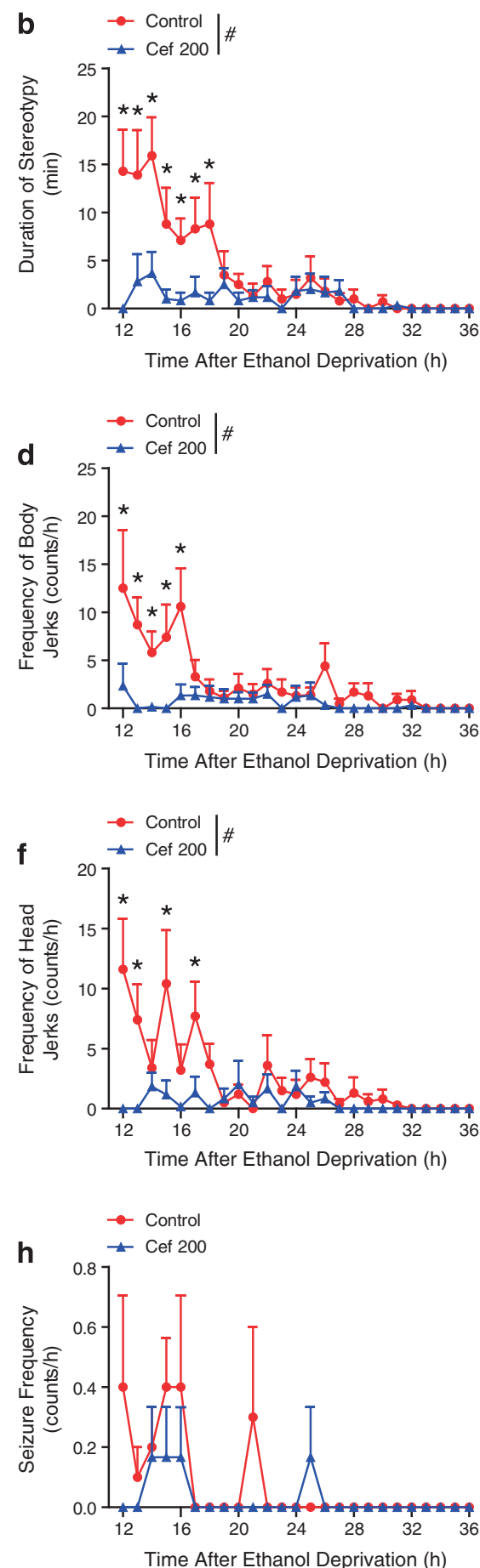

Figure 2 Amelioration of alcohol withdrawal by ceftriaxone $200 \mathrm{mg} / \mathrm{kg} /$ day in alcohol-preferring (P) and Wistar rats. Stereotypy was almost completely eliminated by two-day ceftriaxone $(200 \mathrm{mg} / \mathrm{kg}$ ) treatment in $\mathrm{P}$ rats (a) and substantially reduced in Wistar rats (b) compared to saline-treated counterparts. Myoclonic body jerks were abolished in P rats (c) and diminished in Wistar rats (d) by ceftriaxone. Similarly, myoclonic head jerks were absent in ceftriaxonetreated $\mathrm{P}$ rats $(\mathrm{e})$ and greatly reduced in Wistar rats $(\mathrm{f})$ by ceftriaxone. (g) Ceftriaxone eliminated unprovoked startle responses in $\mathrm{P}$ rats, but (h) did not affect the relatively low frequency of spontaneous tonic/clonic seizures in Wistar rats. ${ }^{\#} P<0.05$ by two-way ANOVA; *P $<0.05$ by Tukey posthoc test; $n=6-10$ per rat type. Data is expressed as mean \pm SEM.

significant interaction between treatment and time $\left(\mathrm{F}_{2,57}=14.34, \quad P=0.0004\right)$ on ethanol consumption by two-way ANOVA. Subsequent Tukey's post-hoc testing revealed that $200 \mathrm{mg} / \mathrm{kg} /$ day ceftriaxone completely blocked withdrawal-increased ethanol consumption for Wistar rats $(P>0.05)$, whereas the $100 \mathrm{mg} / \mathrm{kg} / \mathrm{day}$ dose of ceftriaxone did not $(P<0.01)$. These results show that ceftriaxone $(200 \mathrm{mg} / \mathrm{kg} /$ day) is effective in preventing the increase in 
a

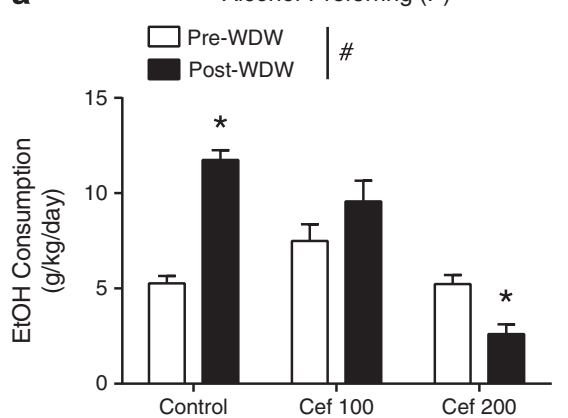

b

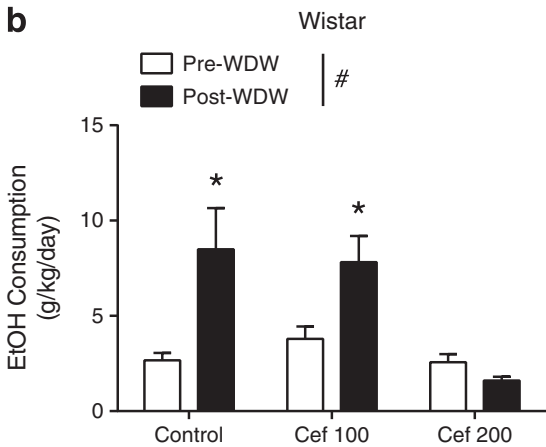

Figure 3 Two-day ceftriaxone $(200 \mathrm{mg} / \mathrm{kg}$ ) administration abolished the increase in ethanol consumption following withdrawal in P rats (a) Two-way ANOVA ${ }^{\#} P<0.000$ I, Tukey's post-hoc test $* P<0.0004$. Ceftriaxone $(200 \mathrm{mg} / \mathrm{kg} /$ day $)$ treatment also reduced post-withdrawal ethanol consumption by Wistar rats (b) Two-way ANOVA ${ }^{*} P=0.032$, Tukey's post-hoc test $* P<0.018$. Note that ceftriaxone $100 \mathrm{mg} / \mathrm{kg} / \mathrm{day}$ did not show significant effect on post withdrawal ethanol consumption in $P$ rats $(P>0.05)$, but with significant increase compared to saline-treated rats $(P<0.05)$. Data is expressed as mean \pm SEM.

a
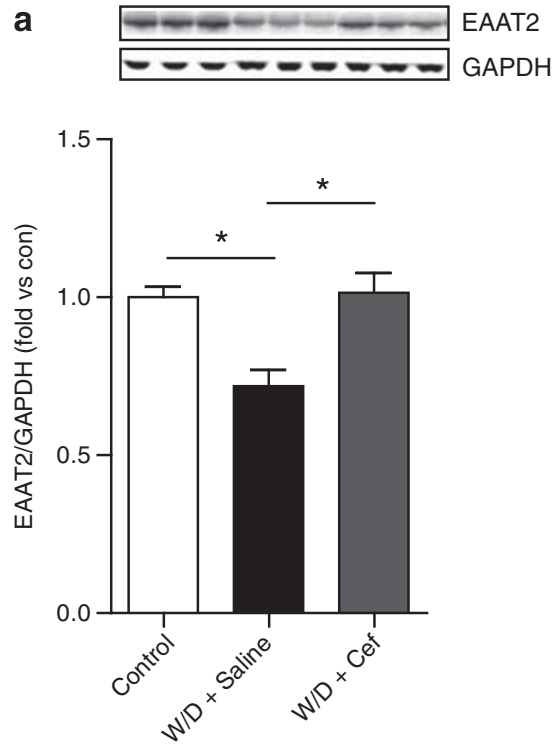

b
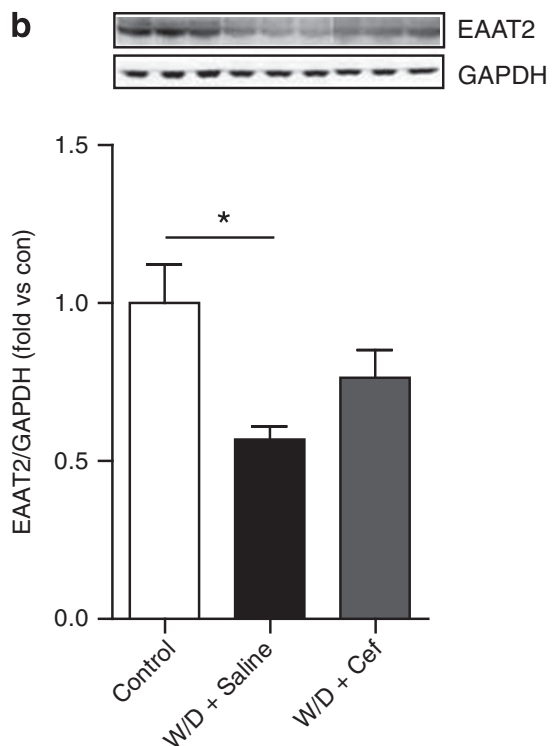

Figure 4 Ethanol withdrawal is associated with significant down regulation of the expression of EAAT2 in the striatum (a) One-way ANOVA followed by posthoc unpaired t-test ( $* P=0.002)$, and the $\mathrm{mPFC}(\mathrm{b})(* P=0.017)$. Two-day ceftriaxone $(200 \mathrm{mg} / \mathrm{kg})$ treatment upregulated EAAT2 protein levels in the striatum (a) $(* P<0.05)$, but not in the mPFC $(P>0.05)$, (b) of rats seven days following alcohol deprivation. Data is expressed as mean $\pm S E M$.

ethanol consumption that follows severe ethanol withdrawal.

\section{Lasting Upregulation of EAAT2 in the Striatum Following 2-Day Ceftriaxone Treatment}

Expression levels of the high-affinity glutamate transporter (EAAT2) in the striatum are upregulated by ceftriaxone treatment in mice (Lee et al, 2013). However, it remained unknown whether ethanol withdrawal regulates EAAT2 expression. Thus, we examined if ethanol withdrawal downregulates EAAT2 expression in the striatum or mPFC of $P$ and Wistar rats. One-way ANOVA showed a significant main effect of withdrawal on EAAT2 expression in both the striatum $\left(\mathrm{F}_{2,12}=10.86, P=0.002\right)$ and the $\operatorname{mPFC}\left(\mathrm{F}_{2,12}\right.$ $=5.74, P=0.017)$. Tukey's post-hoc tests revealed that EAAT2 expression was downregulated in the ethanol with- drawal group in both the striatum (Figure $4 \mathrm{a}$ ) and mPFC (Figure 4b). Next, we examined if ceftriaxone was able to prevent this withdrawal-decreased EAAT2 expression. We found that $200 \mathrm{mg} / \mathrm{kg} /$ day for 2 days increased EAAT2 expression. One-way ANOVA indicates significant main effects of treatment $\left(\mathrm{F}_{2,12}=10.86, P=0.002\right)$. Interestingly, 7 days following the last ceftriaxone injection, EAAT2 expression were still elevated in the striatum (Figure 4a), but not in the mPFC (Figure $4 \mathrm{~b}$ ) compared with saline-treated rats. These data show that EAAT2 upregulation in the striatum lasts as long as 1 week after ceftriaxone treatment.

\section{DISCUSSION}

This study provides compelling evidence for the use of ceftriaxone as an effective method to treat acute alcohol withdrawal and prevent withdrawal-induced escalation in ethanol intake. Using a novel, translational approach to rate 
behavioral manifestations of ethanol withdrawal, we report for the first time a markedly different time course for withdrawal manifestations in Wistar $v s \mathrm{P}$ rats. In addition, we found that ceftriaxone administered during acute ethanol withdrawal induced a lasting upregulation of the glutamate transporter, EAAT2, in the striatum.

In our study, we developed a novel method for rating ethanol withdrawal manifestations based on quantifying individual behaviors over the complete duration of ethanol withdrawal using continuous video recording. An important advantage of the method described here is its vastly greater temporal resolution for the appearance and cessation of individual withdrawal manifestations. The enhanced temporal resolution gives a more complete picture of withdrawal than previous studies, which relied upon short-term observations ( $15 \mathrm{~s}$ ) at various time points after cessation of alcohol administration (Lal et al, 1988; Waller et al, 1982). We also focused on objectively defined, clinically relevant measures of withdrawal rather than more subjective measures such as hyperactivity or twitches. Finally, we did not collapse all withdrawal signs into one score (Majchrowicz and Hunt, 1976). Instead, each withdrawal manifestation was scored individually, allowing for a more robust description and a greater clinical translation.

Perhaps the most fascinating finding in this study is the marked difference observed in the timing of withdrawal symptoms in Wistar vs $\mathrm{P}$ rats. All measures of withdrawal in Wistar rats occurred primarily within the first $24 \mathrm{~h}$ after cessation of alcohol administration, peaking approximately between 12 and $20 \mathrm{~h}$, with almost no symptoms present thereafter. In contrast, P rats showed a surprisingly late onset for withdrawal manifestation, with few if any behavioral changes until nearly a full $24 \mathrm{~h}$ following alcohol deprivation, and peaking well into the second day of withdrawal. To our knowledge, such prolonged withdrawal has not been documented before in $\mathrm{P}$ rats, which may be attributed to the relatively narrow window of observations in previous studies (Lal et al, 1988; Majchrowicz and Hunt, 1976; Waller et al, 1982). Moreover, our results are unlikely to be explained by differences in ethanol elimination between Wistar and $\mathrm{P}$ rats, as $\mathrm{P}$ rats display equal or faster ethanol elimination compared with Wistar rats (Lumeng and Li, 1986) and thus, it would be expected that withdrawal manifestations would present sooner in $\mathrm{P}$ rats than in Wistar rats. In addition, blood ethanol levels may not be attributed to the difference since nearly $25 \%$ of the rats died in both rat types during intoxication when we used the maximal tolerable dose of ethanol. Evidence from microdialysis studies of the striatum (Rossetti and Carboni, 1995), on chronically alcoholized rats after ethanol withdrawal have shown that glutamate levels increase significantly approximately $6 \mathrm{~h}$ after withdrawal, and reach a peak at $12 \mathrm{~h}$, then decline to baseline values at $24 \mathrm{~h}$. This pattern was close to what we observed in Wistar rats, however, in $\mathrm{P}$ rats withdrawal manifestations were observed after a longer delay. Although a clear understanding for this intriguing observation is lacking, recent evidence suggested that $\mathrm{P}$ rats are homozygous for a Grm2 stop codon (Grm2 *407), which encodes metabotropic glutamate receptor 2 (mGluR2), leading to an uncompensated loss of mGluR2, which could be associated with reduced post-synaptic glutamate receptor sensitivity and the longer time course to withdrawal in this strain of rats (Zhou et al, 2013).
To our knowledge, our study is the first to characterize a withdrawal syndrome in Wistar rats. These rats are moderate ethanol consumers, drinking roughly half the amount of ethanol that $\mathrm{P}$ rats consume under basal conditions (2-3 g/ $\mathrm{kg} /$ day compared with $5-6 \mathrm{~g} / \mathrm{kg} /$ day; Figure 3 ). Whether a similar temporal disparity exists for withdrawal or hangover in moderate or social drinkers $v s$ alcohol dependents is unknown, but may have important implications regarding future drinking episodes, as withdrawal is believed to have an important role in the pathophysiology of alcoholism (Ripley and Stephens, 2011).

Interestingly, Wistar and $\mathrm{P}$ rats exhibited a slightly different profile of withdrawal manifestations, with head and body jerks predominating in $\mathrm{P}$ rats, while seizure activity, although infrequent, was only observed in Wistar rats. Similarly, the severity of symptoms was different between Wistar and $\mathrm{P}$ rats, with $\mathrm{P}$ rats showing overall higher levels of withdrawal. The neurological basis for these differences is unclear and warrants further investigation. Considering the differential timescale for withdrawal manifestation between Wistar and P rats, our data also suggest that although a hyperglutamatergic state is clearly implicated in both expressions of withdrawal, different mechanisms may be responsible in social drinkers $v s$ alcohol dependents.

We found that ceftriaxone $200 \mathrm{mg} / \mathrm{kg} /$ day (but not $100 \mathrm{mg} /$ $\mathrm{kg}$ /day) administered during acute alcohol withdrawal almost completely abolished all measured withdrawal manifestations. Our findings are in agreement with the large body of evidence that supports the hypothesis that ethanol withdrawal results from a rebound hyperglutamatergic state unmasked by the abrupt termination of ethanol intake (Chandler et al, 2006; Crews et al, 1996; De Witte et al, 2003; Grant and Lovinger, 1995). Furthermore, our results are in agreement with previous reports showing that ceftriaxone administration displayed anti-seizure properties in an invertebrate assay (Rawls et al, 2010a), reduced the frequency of seizure in a mouse model of tuberous sclerosis complex (Zeng et al, 2010), and reduced cumulative posttraumatic seizure duration in rats (Goodrich et al, 2013). In addition, ceftriaxone $(150,200 \mathrm{mg} / \mathrm{kg})$ injected once daily during chronic morphine exposure inhibited each naloxone-precipitated withdrawal sign (Rawls et al, 2010b), improved mechanical allodynia and attenuated morphine tolerance in an animal model of neuropathic pain (Rawls et al, 2010c), and reduced opioid-induced hyperalgesia in mice (Chen et al, 2012).

The present findings are in concurrence with Krupitsky et al (2007), who demonstrated the superior efficacy of three antiglutamatergic strategies, the glutamate release inhibitor, lamotrigine; the $\mathrm{N}$-methyl-D-aspartate glutamate receptor antagonist, memantine; and the AMPA/kainite receptor inhibitor, topiramate, in ameliorating observer-rated and self-rated withdrawal severity, dysphoric mood, and supplementary diazepam administration in a placebo-controlled study (Krupitsky et al, 2007). A major advantage of ceftriaxone compared with these other antiglutamatergic medications and benzodiazapines is the relatively benign side effect profile.

Interestingly, ceftriaxone blocked the unprovoked startle response, which resembles anxiety and panic-like behavior in humans. Recent evidence suggested that alcohol withdrawalrelated anxiety may stem from increased concentrations 
of synaptic glutamate in the thalamic afferents to the basolateral amygdala during alcohol withdrawal (Christian et al, 2013) or in the dorsal peri-aqueductal gyre matter (Ezequiel Leite and Nobre, 2012). Clinically, anxiety during alcohol hangover is thought to increase the probability of relapse (McGuinness and Fogger, 2006).

One limitation of our study is that we could not establish a clear and robust dose-response relationship with only two doses of ceftriaxone (100 and $200 \mathrm{mg} / \mathrm{kg} /$ day). The $200 \mathrm{mg}$ dose showed a consistent significant efficacy in reducing the severity of withdrawal, whereas the $100 \mathrm{mg}$ dose was only effective for certain withdrawal domains in the Wistar rats. It is interesting that the lower dose of ceftriaxone prevented some, but not all, withdrawal symptoms and had no effect on drinking. This may suggest that not all withdrawal symptoms are regulated by glutamate or related to the motivation to drink. Further studies designed to clarify the dose-response relationship of ceftriaxone for individual withdrawal manifestations are needed.

Importantly, ceftriaxone treatment $200 \mathrm{mg} / \mathrm{kg} / \mathrm{day}$ (but not $100 \mathrm{mg} / \mathrm{kg} /$ day) during the 2-day withdrawal period completely blocked relapse-like ethanol drinking in both rat types. The finding that post-withdrawal drinking in $\mathrm{P}$ rats was much higher than that in Wistar rats also supports the connection between the severity of withdrawal, greater in $\mathrm{P}$ rats, and later drinking episodes. Together with the differential timescale for withdrawal manifestations between the two rat types, our results are consistent with other studies showing a later peak in relapse-like drinking in alcohol-dependent $\mathrm{P}$ rats compared with Wistar rats in an operant paradigm (Gilpin et al, 2008). It is especially noteworthy that post-withdrawal drinking in ceftriaxonetreated $\mathrm{P}$ rats was comparable to basal Wistar rat drinking levels (2-3 g/kg/day). In a study by Gilpin et al (2008), even non-dependent $\mathrm{P}$ rats maintained alcohol consumption approximately twice that of Wistar rats. Thus, the present findings suggest that ceftriaxone could be beneficial not only to curb alcohol deprivation-induced increases in drinking, but to initiate moderate consumption as well, even in a model of alcohol dependence. Taken together, it is plausible to speculate that the ability of ceftriaxone to attenuate alcohol withdrawal manifestations, specially anxiety-like behavior and post-withdrawal ethanol consumption, could be clinically relevant and warrant a proof of concept study to test the efficacy of ceftriaxone in treating alcohol withdrawal and preventing post-withdrawal relapse in humans. In support of this novel concept, the results of a recent multi-phase randomized trial of ceftriaxone in another hyperglutamatergic neuropsychiatric disorder; amyotrophic lateral sclerosis provided valuable information about tolerability and the pharmacokinetics $(\mathrm{PK})$ in patients without inflamed meninges, since original ceftriaxone PK studies were carried in patients with meningitis or healthy volunteers (Perry and Schentag, 2001). The main adverse effects in ceftriaxone-treated subjects were abdominal pain and cholelithiasis (Berry et al, 2013). Of note, in this seminal study, the authors administered ceftriaxone 2-4 gm/day for 20 weeks, which could explain the occurrence of biliary sludge in their study population. Such an adverse event would not be a concern in patients with alcohol withdrawal given the short duration of treatment required. Another concern related to the potential inefficacy of ceftriaxone in patients with alcohol withdrawal. To address this, we recommend use of ceftriaxone as adjunctive to symptom-triggered benzodiazepine treatment to ensure safety in the initial studies using ceftriaxone to treat alcohol withdrawal.

Our data also showed upregulation of EAAT2 in the striatum, but not the $\mathrm{MPFC}$, in ceftriaxone-treated rats. There is mounting evidence documenting that the loss of glutamatergic balance in the corticostriatal neurocircuitry may be a major consequence of alcohol dependence and a key pathophysiological mechanism mediating increased propensity to relapse. Meinhardt et al (2013) have recently shown that chronic intermittent ethanol intoxication resulted in a deficit in mGluR2 on the pyramidal neurons of the PFC and the escalation of ethanol-seeking behavior that can be abolished by restoring mGluR2 expression in the PFC via viral-mediated gene transfer. In addition, Bauer et al (2013) quantified glutamate levels immediately after detoxification in alcohol-dependent patients and in healthy control subjects using proton magnetic resonance spectroscopy and found significantly elevated glutamate levels in the ventral striatum that correlated positively with craving scores. Our findings not only confirm previous studies showing EAAT2 upregulation by ceftriaxone (Abulseoud et al, 2012; Lee et al, 2013; Rothstein et al, 2005), but also demonstrate that this molecular outcome is relatively long lasting (a full week following the last ceftriaxone dose). Moreover, in this study, we gave ceftriaxone for only 2 days, compared with the 3- to 5-day treatments previously associated with EAAT2 upregulation and prevention of addictive behavior (Abulseoud et al, 2012; Sari et al, 2011). It is noteworthy that the brain region specificity of the present observation contrasts with our previous report (Abulseoud et al, 2012), where we showed that ceftriaxone upregulated EAAT2 in the MPFC, but not in the NAc, at $72 \mathrm{~h}$ following the last dose of ceftriaxone in methamphetaminetreated rats. The basis for this disparity between this study and our previous one may involve duration of ceftriaxone administration ( 2 days in this study $v s 7$ days in the methamphetamine study), sampling time (7 days after vs 3 days after the final ceftriaxone dose), or the differential effects of alcohol $v s$ methamphetamine on EAAT2 expression or glutamate signaling in corticostriatal circuitry. In contrast to other studies suggesting that ethanol does not affect EAAT2 levels in the NAc (Melendez et al, 2005) and that there are no changes in glutamate transporter levels or function in the cortex of male rats after 3 days of ethanol withdrawal (Alele and Devaud, 2005), we found significant downregulation of EAAT2 in both the striatum and the $\mathrm{mPFC}$ during ethanol withdrawal. Ceftriaxone was able to rescue the ethanol withdrawal-induced downregulation of EAAT2 only in the striatum and not in the mPFC. This differential effect could be due to the fact that ethanol withdrawal is associated with elevated striatal (Dahchour and De Witte, 1999; Dahchour et al, 1998, Rossetti and Carboni, 1995), but not PFC (Hinton et al, 2012) glutamate levels and reduced EAAT2 expression in the striatum (Wu et al, 2010). Our results differed from Sari et al (2011), where ceftriaxone administration to alcohol $\mathrm{P}$ rats was associated with upregulation of EAAT2 expression in both PFC and ventral striatum. However, the rats in our study went through severe withdrawal and received only 2 days of 
ceftriaxone in contrast to the absence of withdrawal and the longer (5 days) exposure to ceftriaxone as described by Sari's group (Sari et al, 2011). Although it is unknown whether EAAT2 expression or function is affected by binge ethanol administration, our results support the hypothesis that EAAT2 upregulation and enhancement of glutamate uptake is effective in blocking ethanol withdrawal syndrome and withdrawal-escalated drinking.

Interestingly, a recent study showed that the mice lacking EAAT1 (GLAST) displayed reduced reward-seeking behavior and alcohol consumption compared with wild-type mice (Karlsson et al, 2012). Considering the overlapping role of EAAT1 and EAAT2 in the striatum in up-taking extracellular or synaptic glutamate, this finding appears controversial as the deletion of EAAT1 may be expected to increase glutamate levels and then lead to increases alcohol consumption. However, EAAT2/GLT1 is the predominant transporter of glutamate in the forebrain and the striatum, whereas EAAT1/ GLAST is the predominant transporter of glutamate in the cerebellum (Bauer et al, 2012, Whitelaw and Robinson, 2013). Thus, it could be speculated that the role of EAAT1 in the striatum may be different than EAAT2, possibly opposing EAAT2 for fine regulation or extra-synaptic glutamate uptake for feedback inhibition of EAAT2 function. However, further studies are needed to test this hypothesis.

We observed significant weight loss during the intoxication and withdrawal intervals in the saline and ceftriaxone-treated rats compared with control rats (Supplementary Figure 2). In the Wistar rats, a main effect of treatment $\left(\mathrm{F}_{2,52}=64.35\right.$, $P<0.0001)$, time $\left(\mathrm{F}_{2,104}=47.63, P<0.0001\right)$, and an interaction between treatment and time $\left(\mathrm{F}_{24,104}=2.06, P=0.006\right.$; Supplementary Figure S2B) were evident by two-way ANOVA, but this did not reach significance in the $\mathrm{P}$ rats $\left(\mathrm{F}_{13,56}=1.54, \quad P=0.13\right.$; Supplementary Figure $\left.\mathrm{S} 2 \mathrm{~A}\right)$. As reported previously, alcohol intoxication and withdrawal can be associated with weight loss (Wood et al, 1982). Ceftriaxone administration for a few days is not known to be associated with weight loss (Sari et al, 2011). Ceftriaxone administration in our study was associated with mild diarrhea, which has been clinically documented in about $4 \%$ of cases (File et al, 1984).

In summary, our study is highly supportive of the use of ceftriaxone as a novel medication to treat acute ethanol withdrawal and to prevent relapse-like alcohol drinking. We also confirmed downregulation of EAAT2 by ethanol withdrawal and lasting upregulation of EAAT2 in the striatum by ceftriaxone treatment, which coincides with reduced ethanol consumption in rats. Furthermore, we describe a useful new method to monitor alcohol withdrawal based upon clinically relevant behavioral manifestations with much greater temporal resolution than previous techniques, which led to the discovery of differences in the time course and severity of ethanol withdrawal in a moderate drinking $v s$ an alcohol-dependent animal model. This may have important implications for the timing and/or length of treatment in withdrawn individuals based upon their history of alcohol use. Regardless of prior drinking patterns, however, this study demonstrates that enhancement of glutamate uptake in the striatum is an effective strategy to prevent AWS and the heavy drinking that frequently follows. Further studies designed specifically to explore other mechanisms including upregulation of the water channel AQP-4 (Lee et al, 2013) and address the relationship between behavioral changes and changes in EAAT2 levels are highly needed.

\section{FUNDING AND DISCLOSURE}

The authors declare no conflict of interest.

\section{ACKNOWLEDGEMENTS}

We acknowledge Dr Lawrence Lumeng, MD and Dr Zachary Rodd, $\mathrm{PhD}$ for their kind support in providing the alcoholpreferring rats under the NIAAA-(R24 AA015512) mechanism. We thank Dr Ahmed T Ahmed, MBBCh for assistance with the experiments. This work was supported by $\mathrm{NIH} /$ NCRR CTSA KL2 (RR024151 to OAA) and was supported in part by Samuel C Johnson Genomics of Addiction Program at Mayo and by NIH (AA018779 to D-SC).

\section{Author contributions}

OAA conceived and designed behavioral experiments. OAA, D-SC and CLR designed molecular experiments. OAA and UMC performed withdrawal monitoring experiments. AK performed ethanol-drinking experiments. SC performed western blotting. OAA, AK and CLR performed statistical analysis, prepared figures and wrote the manuscript. All authors contributed to reviewing and editing the manuscript.

\section{REFERENCES}

Abulseoud OA, Miller JD, Wu J, Choi DS, Holschneider DP (2012). Ceftriaxone upregulates the glutamate transporter in medial prefrontal cortex and blocks reinstatement of methamphetamine seeking in a condition place preference paradigm. Brain Res 1456: 14-21.

Alele PE, Devaud LL (2005). Differential adaptations in GABAergic and glutamatergic systems during ethanol withdrawal in male and female rats. Alcoholism Clin Exp Res 29: 1027-1034.

Amato L, Minozzi S, Davoli M (2011). Efficacy and safety of pharmacological interventions for the treatment of the alcohol withdrawal syndrome. Cochrane Database Syst Rev CD008537.

Bauer DE, Jackson JG, Genda EN, Montoya MM, Yudkoff M, Robinson MB (2012). The glutamate transporter, GLAST, participates in a macromolecular complex that supports glutamate metabolism. Neurochem Int 61: 566-574.

Bauer J, Pedersen A, Scherbaum N, Bening J, Patschke J, Kugel H et al (2013). Craving in alcohol-dependent patients after detoxification is related to glutamatergic dysfunction in the nucleus accumbens and the anterior cingulate cortex. Neuropsychopharmacology 38: 1401-1408.

Berry JD, Shefner JM, Conwit R, Schoenfeld D, Keroack M, Felsenstein D et al Northeast ALS Consortium (2013). Design and initial results of a multi-phase randomized trial of ceftriaxone in amyotrophic lateral sclerosis. PLoS One 8: e61177.

Campos J, Roca L, Gude F, Gonzalez-Quintela A (2011). Long-term mortality of patients admitted to the hospital with alcohol withdrawal syndrome. Alcohol Clin Exp Res 35: 1180-1186.

Chandler LJ, Carpenter-Hyland E, Hendricson AW, Maldve RE, Morrisett RA, Zhou FC et al (2006). Structural and functional modifications in glutamateric synapses following prolonged ethanol exposure. Alcohol Clin Exp Res 30: 368-376. 
Chen Z, He Y, Wang ZJ (2012). The beta-lactam antibiotic, ceftriaxone, inhibits the development of opioid-induced hyperalgesia in mice. Neurosci Lett 509: 69-71.

Christian DT, Alexander NJ, Diaz MR, McCool BA (2013). Thalamic glutamatergic afferents into the rat basolateral amygdala exhibit increased presynaptic glutamate function following withdrawal from chronic intermittent ethanol. Neuropharmacology 65: 134-142.

Collins MA, Corso TD, Neafsey EJ (1996). Neuronal degeneration in rat cerebrocortical and olfactory regions during subchronic 'binge' intoxication with ethanol: possible explanation for olfactory deficits in alcoholics. Alcohol Clin Exp Res 20: 284-292.

Crews FT, Buckley T, Dodd PR, Ende G, Foley N, Harper C et al (2005). Alcoholic neurobiology: changes in dependence and recovery. Alcohol Clin Exp Res 29: 1504-1513.

Crews FT, Morrow AL, Criswell H, Breese G (1996). Effects of ethanol on ion channels. Int Rev Neurobiol 39: 283-367.

Dahchour A, De Witte P, Bolo N, Nédélec JF, Muzet M, Durbin P et al (1998). Central effects of acamprosate: part 1. Acamprosate blocks the glutamate increase in the nucleus accumbens microdialysate in ethanol withdrawn rats. Psychiatry Res 82: 107-114.

Dahchour A, De Witte P (1999). Effect of repeated ethanol withdrawal on glutamate microdialysate in the hippocampus. Alcohol Clin Exp Res 23: 1698-1703.

De Witte P, Pinto E, Ansseau M, Verbanck P (2003). Alcohol and withdrawal: from animal research to clinical issues. Neurosci Biobehav Rev 27: 189-197.

Ezequiel Leite L, Nobre MJ (2012). The negative effects of alcohol hangover on high-anxiety phenotype rats are influenced by the glutamate receptors of the dorsal midbrain. Neuroscience 213: 93-105.

File TM Jr, Tan JS, Salstrom SJ (1984). Clinical evaluation of ceftriaxone. Clin Ther 6: 653-661.

Gerfen CR, Surmeier DJ (2011). Modulation of striatal projection systems by dopamine. Annu Rev Neurosci 34: 441-466.

Gilpin NW, Richardson HN, Lumeng L, Koob GF (2008). Dependence-induced alcohol drinking by alcohol-preferring (P) rats and outbred Wistar rats. Alcohol Clin Exp Res 32: 1688-1696.

Goodrich GS, Kabakov AY, Hameed MQ, Dhamne SC, Rosenberg PA, Rotenberg A (2013). Ceftriaxone treatment after traumatic brain injury restores expression of the glutamate transporter, GLT-1, reduces regional gliosis, and reduces post-traumatic seizures in the rat. J Neurotrauma 30: 1434-1441.

Grant KA, Lovinger DM (1995). Cellular and behavioral neurobiology of alcohol: receptor-mediated neuronal processes. Clin Neurosci New York, NY 3: 155-164.

Hinton DJ, Lee MR, Jacobson TL, Mishra PK, Frye MA, Mrazek DA et al (2012). Ethanol withdrawal-induced brain metabolites and the pharmacological effects of acamprosate in mice lacking ENT1. Neuropharmacology 62: 2480-2488.

Holmseth S, Zhou Y, Follin-Arbelet VV, Lehre KP, Bergles DE, Danbolt NC (2012). Specificity controls for immunocytochemistry: the antigen preadsorption test can lead to inaccurate assessment of antibody specificity. J Histochem Cytochem 60: 174-187.

Kampov-Polevoy AB, Matthews DB, Gause L, Morrow AL, Overstreet DH (2000). P rats develop physical dependence on alcohol via voluntary drinking: changes in seizure thresholds, anxiety, and patterns of alcohol drinking. Alcohol Clin Exp Res 24: 278-284.

Karlsson RM, Adermark L, Molander A, Perreau-Lenz S, Singley E, Solomon $\mathrm{M}$ et al (2012). Reduced alcohol intake and reward associated with impaired endocannabinoid signaling in mice with a deletion of the glutamate transporter GLAST. Neuropharmacology 63: 181-189.

Knackstedt LA, Melendez RI, Kalivas PW (2010). Ceftriaxone restores glutamate homeostasis and prevents relapse to cocaine seeking. Biol Psychiatry 67: 81-84.
Krupitsky EM, Rudenko AA, Burakov AM, Slavina TY, Grinenko AA, Pittman B et al (2007). Antiglutamatergic strategies for ethanol detoxification: comparison with placebo and diazepam. Alcohol Clin Exp Res 31: 604-611.

Lal H, Harris CM, Benjamin D, Springfield AC, Bhadra S, EmmettOglesby MW (1988). Characterization of a pentylenetetrazol-like interoceptive stimulus produced by ethanol withdrawal. J Pharmacol Exp Ther 247: 508-518.

Lee MR, Ruby CL, Hinton DJ, Choi S, Adams CA, Young Kang N et al (2013). Striatal adenosine signaling regulates EAAT2 and astrocytic AQP4 expression and alcohol drinking in mice. Neuropsychopharmacology 38: 437-445.

Leggio L, Kenna GA, Swift RM (2008). New developments for the pharmacological treatment of alcohol withdrawal syndrome. A focus on non-benzodiazepine GABAergic medications. Prog Neuropsychopharmacol Biol Psychiatry 32: 1106-1117.

Lumeng L, Li TK (1986). The development of metabolic tolerance in the alcohol-preferring $P$ rats: comparison of forced and free-choice drinking of ethanol. Pharmacol Biochem Behav 25: 1013-1020.

Majchrowicz E, Hunt WA (1976). Temporal relationship of the induction of tolerance and physical dependence after continuous intoxication with maximum tolerable doses of ethanol in rats. Psychopharmacology 50: 107-112.

Malcolm RJ (2003). GABA systems, benzodiazepines, and substance dependence. J Clin Psychiatry 64(Suppl 3): 36-40.

McGuinness TM, Fogger SA (2006). Hyper-anxiety in early sobriety: psychopharmacological treatment strategies. J Psychosoc Nurs Ment Health Serv 44: 22-27.

Meinhardt MW, Hansson AC, Perreau-Lenz S, Bauder-Wenz C, Stählin O, Heilig M et al (2013). Rescue of infralimbic mGluR2 deficit restores control over drug-seeking behavior in alcohol dependence. J Neurosci 33: 2794-2806.

Melendez RI, Hicks MP, Cagle SS, Kalivas PW (2005). Ethanol exposure decreases glutamate uptake in the nucleus accumbens. Alcoholism Clin Exp Res 29: 326-333.

Nixon K, Crews FT (2004). Temporally specific burst in cell proliferation increases hippocampal neurogenesis in protracted abstinence from alcohol. J Neurosci 24: 9714-9722.

Perry TR, Schentag JJ (2001). Clinical use of ceftriaxone: a pharmacokinetic-pharmacodynamic perspective on the impact of minimum inhibitory concentration and serum protein binding. Clin Pharmacokinet 40: 685-694.

Plant M, Miller P, Plant M, Gmel G, Kuntsche S, Bergmark WK et al (2012). The social consequences of binge drinking among 24- to 32-year-olds in six European countries. Substance Use Misuse 45: 528-542.

Rawls SM, Karaca F, Madhani I, Bhojani V, Martinez RL, Abou-Gharbia M et al (2010a). Beta-lactamase inhibitors display anti-seizure properties in an invertebrate assay. Neuroscience 169: $1800-1804$

Rawls SM, Baron DA, Kim J (2010b). Beta-lactam antibiotic inhibits development of morphine physical dependence in rats. Behav Pharmacol 21: 161-164.

Rawls SM, Zielinski M, Patel H, Sacavage S, Baron DA, Patel D (2010c). Beta-lactam antibiotic reduces morphine analgesic tolerance in rats through GLT-1 transporter activation. Drug Alcohol Depend 107: 261-263.

Ripley TL, Stephens DN (2011). Critical thoughts on current rodent models for evaluating potential treatments of alcohol addiction and withdrawal. Br J Pharmacol 164: 1335-1356.

Rossetti ZL, Carboni S. (1995). Ethanol withdrawal is associated with increased extracellular glutamate in the rat striatum. Eur J Pharmacol 283: 177-183.

Rothstein JD, Patel S, Regan MR, Haenggeli C, Huang YH, Bergles $\mathrm{DE}$ et al (2005). Beta-lactam antibiotics offer neuroprotection by increasing glutamate transporter expression. Nature 433: 73-77. Sari Y, Sakai M, Weedman JM, Rebec GV, Bell RL (2011). Ceftriaxone, a beta-lactam antibiotic, reduces ethanol consump- 
tion in alcohol-preferring rats. Alcohol Alcohol (Oxford, Oxfordshire) 46: 239-246.

Sari Y, Sreemantula SN, Lee MR, Choi DS (2013). Ceftriaxone treatment affects the levels of GLT1 and ENT1 as well as ethanol intake in alcohol-preferring rats. J Mol Neurosci 51: 779-787.

Tsai GE, Ragan P, Chang R, Chen S, Linnoila VM, Coyle JT (1998). Increased glutamatergic neurotransmission and oxidative stress after alcohol withdrawal. Am J Psychiatry 155: 726-732.

Waller MB, McBride WJ, Lumeng L, Li TK (1982). Induction of dependence on ethanol by free-choice drinking in alcoholpreferring rats. Pharmacol Biochem Behav 16: 501-507.

Whitelaw BS, Robinson MB (2013). Inhibitors of glutamate dehydrogenase block sodium-dependent glutamate uptake in rat brain membranes. Front Endocrinol (Lausanne) 4: 123.
Wood WG, Armbrecht HJ, Wise RW (1982). Ethanol intoxication and withdrawal among three age groups of C57BL7/6NNIA mice. Pharmacol Biochem Behav 17: 1037-1041.

Wu J, Lee MR, Choi S, Kim T, Choi DS (2010). ENT1 regulates ethanol-sensitive EAAT2 expression and function in astrocytes. Alcohol Clin Exp Res 34: 1110-1117.

Zeng LH, Bero AW, Zhang B, Holtzman DM, Wong M (2010). Modulation of astrocyte glutamate transporters decreases seizures in a mouse model of tuberous sclerosis complex. Neurobiol Dis 37: 764-771.

Zhou Z, Karlsson C, Liang T, Xiong W, Kimura M, Tapocik JD et al (2013). Loss of metabotropic glutamate receptor 2 escalates alcohol consumption. Proc Natl Acad Sci USA 110: 16963-16968.

Supplementary Information accompanies the paper on the Neuropsychopharmacology website (http://www.nature.com/npp) 